Elsevier required licence: $(c)<2016>$. This manuscript version is made available under the CC-BY-NC-ND 4.0 license http://creativecommons.org/licenses/by-nc-nd/4.0/ 


\title{
Selective sorption of rubidium by potassium cobalt hexacyanoferrate
}

Gayathri Naidu, Tanjina Nur, Paripurnanda Loganathan, Jaya Kandasamy, Saravanamuthu

Vigneswaran*

Faculty of Engineering, University of Technology Sydney (UTS), P.O. Box 123, Broadway, NSW 2007

Australia,

*Corresponding author: Tel +61-2-9514-2641; Fax +61-2-9514-2633; Email:

Saravanamuth.Vigneswaran@uts.edu.au

\begin{abstract}
Recovering economically valuable rubidium $(\mathrm{Rb})$ from natural resources is challenged due to its low concentration and limited selectivity of extracting agents. Equilibrium and kinetic studies were conducted on the sorptive removal of $\mathrm{Rb}$ at low concentration $(5 \mathrm{mg} / \mathrm{L})$ using a commercial and a laboratory prepared potassium cobalt hexacyanoferrate (KCoFC). These laboratory and commercial KCoFCs exhibited similar characteristics in terms of chemical composition, surface morphology (scanning electron microscopy) and crystal structure (X-ray diffraction peaks). KCoFC exhibited a higher sorption capacity for Rb (Langmuir maximum sorption $96.2 \mathrm{mg} / \mathrm{g}$ ) and cesium (Cs) (Langmuir maximum sorption $60.6 \mathrm{mg} / \mathrm{g}$ ) compared to other metals such as lithium ( $\mathrm{Li}$ ), sodium $(\mathrm{Na})$ and calcium $(\mathrm{Ca})$ (sorption capacity $<2 \mathrm{mg} / \mathrm{g}$ ). KCoFC sorption capacity for $\mathrm{Rb}$ was affected only when $\mathrm{Cs}$ was present at twice the concentration of $\mathrm{Rb}$, while the influence of other metals ( $\mathrm{Li}, \mathrm{Na}$, and $\mathrm{Ca}$ ) was minimal even at high concentrations. High $\mathrm{Rb}$ sorption capacity was due to the exchange of $\mathrm{Rb}$ for $\mathrm{K}$ inside the crystal lattice and strong sorption on the sorbent surface. These were evident from the data on $\mathrm{K}$ release during $\mathrm{Rb}$ sorption and reduced negative zeta potential at the sorbent surface in the
\end{abstract}


presence of $\mathrm{Rb}$, respectively. Kinetic sorption of $\mathrm{Rb}$ was satisfactorily described by the pseudosecond order model with intraparticle diffusion and exchange of $\mathrm{Rb}$ with structural $\mathrm{K}$ acting as major rate limiting steps. Up to $80 \%$ desorption of $\mathrm{Rb}$ was achieved with $0.1 \mathrm{M} \mathrm{KCl}$. Overall, the results established the superior selectivity of $\mathrm{KCOFC}$ for Rb sorption.

Keywords: potassium cobalt hexacyanoferrate; rubidium; sorption isotherm; sorption kinetics

\section{Highlights}

- Potassium cobalt hexacyanoferrate (KCoFC) had high sorption capacity for $\mathrm{Rb}$

- $\mathrm{Rb}$ was selectively sorbed by $\mathrm{KCoFC}$ in the presence of other alkali metals

- Langmuir sorption capacity was higher for $\mathrm{Rb}$ than $\mathrm{Cs}$

- $\mathrm{K}$ release from $\mathrm{KCoFC}$ lattice was highest for $\mathrm{Rb}$ sorption among the alkali metals

- Intra-particle diffusion and lattice $\mathrm{K}$ release controlled $\mathrm{Rb}$ sorption kinetics

\section{Introduction}

In the last few decades attention has been focused on extracting rubidium $(\mathrm{Rb})$ due to its application in many fields of science and technology. $\mathrm{Rb}$ is used in fibre optic telecommunication systems, semiconductor technology and night-vision equipment $[1,2]$. In recent years, new and more efficient techniques have been established in optical and laser application with the usage of warm $\mathrm{Rb}$ vapour $[3,4]$. Although considerable $\mathrm{Rb}$ mineral resources are available, it is much more difficult to extract $\mathrm{Rb}$ than other alkali metals [2]. The application potential coupled with the mineral extraction challenge has increased the economic value of $\mathrm{Rb}$. The price of $\mathrm{Rb}$ is much higher $(€ 7856.64 / \mathrm{kg})$ in comparison to lithium ( $\mathrm{Li})$ $(€ 1.22 / \mathrm{kg})$ and potassium $(\mathrm{K})(€ 0.11 / \mathrm{kg})[5]$.

This has led to the development of new methods for the extraction of $\mathrm{Rb}$ from resources such as oilfield water, mining industry, ores with low Rb content, seawater and salt lakes [2,68]. Potential methods of alkali metal extraction from natural resources include evaporation, 
precipitation, use of emulsion membranes and liquid-liquid extraction techniques $[9,10]$. Nevertheless, the effectiveness of recovering trace metals with these methods are challenged in natural resources by the low concentration of the target metals, the limited selectivity of the extracting agents, and the presence of other constituents. In this regard, inorganic ion-exchange sorbents offer a practical approach in that they have the capacity to selectively extract low concentration metals from mixed solutions [7].

A number of diverse inorganic sorbents have been used for selective alkali metal sorption including Prussian blue [11], potassium metal hexacyanoferrate [12], zeolite [13], titanium dioxide [14] and ammonium molybdophosphate [15]. Most of these studies have focused on the removal of radioactive cesium (Cs) in nuclear waste brine. $\mathrm{Cs}$ and $\mathrm{Rb}$ have similar physico-chemical properties and on this basis, a few studies have examined the prospect of $\mathrm{Rb}$ extraction by sorbents $[5,16]$. These studies have highlighted the high $\mathrm{Rb}$ sorption capacity of potassium metal hexacyanoferrate. However, we still lack a detailed understanding of: firstly, the mechanism and kinetics of Rb sorption by potassium metal hexacyanoferrate; and secondly, the effect of the presence of other alkali metals on Rb sorption. Moreover, these studies were conducted using high concentrations of the target alkali metal in the 20 to $>500$ $\mathrm{mg} / \mathrm{L}$ range. The concentration of the target metal is an important factor in establishing the effective performance of a sorbent. As $\mathrm{Rb}$ is present in a relatively low concentration $(<1.0$ $\mathrm{mg} / \mathrm{L}$ ) in natural resources such as seawater, experiments at high concentration levels may not reflect the performance of the sorbent in a practical scenario. Further, apart from the sorption performance, desorption capacity is an important factor in establishing the viability of a sorbent if the target metal has to be recovered in concentrated form in solutions. This aspect has not been discussed thus far for $\mathrm{Rb}$ sorption with potassium metal hexacyanoferrate.

Hence, the objective of this study was to establish the selective affinity of potassium cobalt hexacyanoferrate (KCoFC) for Rb sorption. The specific objectives were to: (1) synthesise $\mathrm{KCoFC}$ in the laboratory $(\mathrm{KCoFC}(\mathrm{L}))$ and compare its properties and characteristics 
with a commercial $\mathrm{KCoFC}$ sorbent $(\mathrm{KCoFC}(\mathrm{C}))$ in terms of chemical composition, crystal structure, surface area and pore size distribution, surface charge characteristics, and efficiency of $\mathrm{Rb}$ sorption; (2) determine the effect of $\mathrm{pH}$ and co-existing alkali metal ions on $\mathrm{Rb}$ sorption; (3) model the equilibrium and kinetics of $\mathrm{Rb}$ sorption; (4) determine the mechanism of $\mathrm{Rb}$ sorption; and (5) investigate the desorption of $\mathrm{Rb}$ using different acid, alkaline, and salt solutions.

\section{Material and methods}

\subsection{Materials}

\subsubsection{Commercial sorbent $(\mathrm{KCoFC}(\mathrm{C}))$}

$\mathrm{KCoFC}(\mathrm{C})$ also known as CsTreat was supplied by Fortum Engineering Ltd, (Finland). This sorbent consisted of dark brown-black granules ranging in size from 0.25 to $0.85 \mathrm{~mm}$ [17]. The granules were ground to particle sizes of 0.25 to $0.45 \mathrm{~mm}$ for this study.

\subsubsection{Laboratory sorbent $(\mathrm{KCoFC}(L))$}

$\mathrm{KCoFC}(\mathrm{L})$ was prepared in the laboratory by adding 1 volume of $0.5 \mathrm{M}$ potassium ferrocyanide trihydrate $\left(\mathrm{K}_{4} \mathrm{Fe}(\mathrm{CN})_{6} \cdot 3 \mathrm{H}_{2} \mathrm{O}\right)$ to 2.4 volumes of $0.3 \mathrm{M}$ cobalt nitrate hexahydrate $\left(\mathrm{Co}\left(\mathrm{NO}_{3}\right)_{2} \cdot 6 \mathrm{H}_{2} \mathrm{O}\right)$ as described by Prout et al. [18]. The mixture was stirred for $1 \mathrm{~h}$ at room temperature, followed by centrifuging and washing with deionised water. The concentrated mixture was dried at $115^{\circ} \mathrm{C}$ for $24 \mathrm{~h}$. The dried granules were ground to a particle size of 0.25 to $0.45 \mathrm{~mm}$, washed again with deionised water and then dried.

\subsubsection{Solutions}

Stock solutions of $\mathrm{Rb}, \mathrm{Cs}, \mathrm{Li}, \mathrm{K}, \mathrm{Na}$ and $\mathrm{Ca}$ were prepared by dissolving $\mathrm{RbCl}, \mathrm{CsCl}$, $\mathrm{LiCl}, \mathrm{KCl}, \mathrm{NaCl}$ and $\mathrm{CaCl}_{2}$, respectively, in deionised water. All reagents were of analytical grade (Sigma-Aldrich) and were used without further purification. 


\subsection{Sorbent characterisation}

\subsubsection{Chemical analysis}

Samples of KCoFC (0.05 g) were decomposed in $1 \mathrm{~mL}$ of concentrated $\mathrm{H}_{2} \mathrm{SO}_{4}$ by heating at $200^{\circ} \mathrm{C}$ for 5 h. $10 \mathrm{~mL}$ of $0.1 \mathrm{M} \mathrm{H}_{2} \mathrm{SO}_{4}$ was added to the residue, and diluted to 50 $\mathrm{mL}$ with deionised water as per the procedure of Nilchi et al. [19]. Concentrations of K, iron $(\mathrm{Fe})$ and cobalt $(\mathrm{Co})$ in the aqueous samples were measured after filtration through a $1.2 \mu \mathrm{m}$ syringe membrane filter using Microwave Plasma - Atomic Emission Spectroscopy (MP-AES) (Agilent 4100). The procedure was carried out in triplicate and the average results are reported in this study. The deviation between the replicated values was $<10 \%$.

\subsubsection{SEM-EDX analysis}

The morphology and detection of elements on the $\mathrm{KCoFC}$ before and after Rb sorption was carried out with scanning electron microscopy (SEM) coupled with Energy Dispersive Xray spectrometry (EDX) operated at $15 \mathrm{kV}$ (Zeiss Supra 55VP Field Emission).

\subsubsection{Powder X-ray diffraction analysis (XRD)}

XRD data (on powders) were collected on a Siemens D5000 diffractometer operating with $\mathrm{CuKa}$ radiation and a rotating sample stage. The samples were scanned at room temperature in the $2 \Theta$ angular range of $20-110^{\circ}$.

\subsubsection{Surface area and pore volume}

Nitrogen adsorption-desorption on $\mathrm{KCoFC}(\mathrm{C})$ and $\mathrm{KCoFC}(\mathrm{L})$ was determined at $77 \mathrm{~K}$ using the nano POROSITY (Mirae SI, Korea) adsorption analyser. Approximately $0.1 \mathrm{~g}$ of freeze-dried sample was used for the analysis following an overnight degassing at $80^{\circ} \mathrm{C}$ under vacuum. The specific surface area was calculated using the standard Brunauer-Emmett-Teller 
(BET) method. The total pore volume $\left(\mathrm{V}_{\text {tot }}\right)$ was determined from the nitrogen adsorption at a relative pressure of about $\mathrm{p} / \mathrm{p}_{0} \approx 0.99$. Average pore diameter was calculated using the equation, $4 \mathrm{~V}_{\text {tot }} / \mathrm{S}_{\mathrm{BET}}$

\subsection{5. $\mathrm{pH}$ and zeta potential}

To investigate the effect of $\mathrm{pH}$ and zeta potential on sorption, suspensions of $1 \mathrm{~g} / \mathrm{L}$ KCoFC sorbents in different solutions $(100 \mathrm{~mL})$ were agitated for $12 \mathrm{~h}$ in a flat shaker at a shaking speed of $120 \mathrm{rpm}$ at room temperature $\left(24 \pm 1^{\circ} \mathrm{C}\right)$. The $\mathrm{pH}$ values of the feed solution were set in the 3 to 10 range by adjusting the initial $\mathrm{pH}$ using $0.1 \mathrm{M} \mathrm{HCl}$ and $0.1 \mathrm{M} \mathrm{NaOH}$. The initial and final $\mathrm{pHs}$ at the end of the sorption period were measured using a HQ40d portable $\mathrm{pH}$ Meter. To maintain a constant $\mathrm{pH}, \mathrm{pH}$ was adjusted to its initial value after 4 and $8 \mathrm{~h}$ for all sorption experiments. The zeta potential was measured using a Zetasizer nano instrument (Nano ZS Zen3600, Malvern, UK) on the suspensions. Measurements were done in triplicate to minimise undesirable biases (with differences between replicates always being less than 5\%).

\subsection{Sorption experiments}

In view of the low concentrations of $\mathrm{Rb}$ and $\mathrm{Cs}$ in natural resources, and in order to reliably measure the metals concentrations utilising analytical instruments, sorption experiments were carried out at a maximum initial concentration of $5 \mathrm{mg} / \mathrm{L}$ for $\mathrm{Rb}$ and $\mathrm{Cs}$. However, higher concentrations of $\mathrm{Li}, \mathrm{Na}$, and $\mathrm{Ca}$ were used as these metals had very low sorption capacity at low concentrations. All experiments were performed in a set of glass flasks containing $100 \mathrm{~mL}$ of metal solutions and different doses of sorbents agitated in a flat shaker at a shaking speed of $120 \mathrm{rpm}$ at room temperature $\left(24 \pm 1^{\circ} \mathrm{C}\right)$. The experiments were duplicated and the average values were recorded for data analysis. The difference between duplicate values was within $\pm 2 \%$. The concentrations of $\mathrm{Rb}, \mathrm{Li}, \mathrm{Na}$ and $\mathrm{Ca}$ in the supernatants were measured 
using MP-AES. The Cs concentration was measured using ICS-MS (PerkinElmer® NexION® $300)$.

\subsubsection{Sorption isotherms}

Equilibrium sorption experiments were conducted with different doses of sorbent ( $\mathrm{KCoFC}$ ) ranging from 0.02 to $0.20 \mathrm{~g} / \mathrm{L}$ at $\mathrm{pH} 7.0 \pm 0.5$. The suspensions were agitated for 24 $\mathrm{h}$ to reach the sorption equilibrium. The supernatant solution was examined using MP-AES analysis after filtration through a $1.2 \mu \mathrm{m}$ syringe membrane filter. The sorption amount at equilibrium, $\mathrm{q}_{\mathrm{e}}(\mathrm{mg} / \mathrm{g})$, was calculated using Eq. (1):

$$
q_{e}=\frac{\left(C_{0}-C_{e}\right) \cdot V}{M}
$$

where, $\mathrm{C}_{0}$ and $\mathrm{C}_{\mathrm{e}}$ are the initial and equilibrium concentration of ion in the bulk solution $(\mathrm{mg} / \mathrm{L})$, $\mathrm{V}$ is volume of solution ( $\mathrm{L})$ and $\mathrm{M}$ is mass of sorbent $(\mathrm{g})$.

The sorption data were modelled according to Langmuir (Eq. 2) and Freundlich isotherms (Eq. 3) as follows.

$$
\begin{aligned}
& q_{e}=\frac{Q_{\max } K_{L} C_{e}}{1+K_{L} C_{e}} \\
& q_{e}=K_{f} C_{e}^{1 / n} \\
& q_{e}=K_{f} C_{e}^{1 / n}
\end{aligned}
$$

where $\mathrm{Q}_{\max }$ is the maximum sorption capacity $(\mathrm{mg} / \mathrm{g}), \mathrm{K}_{\mathrm{L}}$ is the Langmuir binding constant, which is related to the energy of sorption $(\mathrm{L} / \mathrm{mg}), \mathrm{K}_{\mathrm{f}}$ is the Freundlich constant representing the 
sorption capacity $(\mathrm{mg} / \mathrm{g})(\mathrm{L} / \mathrm{mg})^{1 / \mathrm{n}}$ and $1 / \mathrm{n}$ is a constant inversely related to the sorptive energy between the sorbent and the sorbate (unit-less).

\subsubsection{Sorption kinetics}

Sorption kinetics experiments for $\mathrm{Rb}$ and $\mathrm{Cs}$ were conducted by agitating $\mathrm{KCoFC}$ at a dose of $0.05 \mathrm{~g} / \mathrm{L}$ with $5 \mathrm{mg} / \mathrm{L}$ of $\mathrm{Rb}$ and $\mathrm{Cs}$ in $0.1 \mathrm{~L}$ solution. Samples of the agitated suspensions were taken at different time intervals up to $48 \mathrm{~h}$, filtered, and the filtrate analysed for $\mathrm{Rb}$ and $\mathrm{Cs}$. The sorption amount $\left(\mathrm{q}_{\mathrm{t}}\right)$ at time $\mathrm{t}$ was calculated using Eq. (4):

$$
q_{t}=\frac{\left(C_{0}-C_{t}\right) \cdot V}{M}
$$

where, $\mathrm{C}_{0}$ and $\mathrm{C}_{\mathrm{t}}$ are the initial and final concentrations of metal at time $\mathrm{t}(\mathrm{mg} / \mathrm{L})$.

The sorption data was modelled using pseudo-first order (PFO) and pseudo-second order kinetics (PSO) as described in (Eq. 5) and (Eq. 6) [20].

$$
\begin{aligned}
& \ln \left(q_{e}-q_{t}\right)=\ln q_{e}-k_{1} t \\
& \frac{t}{q_{t}}=\frac{1}{k_{2} q_{e}^{2}}+\frac{1}{q_{e}} t
\end{aligned}
$$

where $\mathrm{q}_{\mathrm{t}}(\mathrm{mg} / \mathrm{g})$ is the adsorption capacity at time $\mathrm{t}(\mathrm{min})$, and $\mathrm{k}_{1}(1 / \mathrm{min})$ and $\mathrm{k}_{2}(\mathrm{~g} / \mathrm{mg} \min )$ are the pseudo-first order and pseudo-second order rate constants, respectively.

The Weber-Morris diffusion model (Eq. 7) was also used to describe the kinetic data [21]:

$$
q_{t}=k_{i} t^{1 / 2}+C
$$

where $\mathrm{k}_{\mathrm{i}}\left(\mathrm{mg} / \mathrm{g} \min ^{0.5}\right)$ is the intra-particle diffusion rate constant and the intercept $\mathrm{C}$ represents the boundary layer thickness. 


\subsection{Desorption}

Initially $\mathrm{Rb}$ was sorbed onto $\mathrm{KCoFC}$ by shaking $0.1 \mathrm{~g} / \mathrm{L}$ dose of the sorbent with $\mathrm{Rb}$ at a concentration of $5 \mathrm{mg} / \mathrm{L}$. Upon saturation of the sorbent with $\mathrm{Rb}$, the sorbent was filtered and dried at room temperature. The amount of $\mathrm{Rb}$ sorbed was determined as explained previously. The $\mathrm{Rb}$ in the sorbent was then desorbed using $0.1 \mathrm{M}$ of $\mathrm{HNO}_{3}, \mathrm{KOH}, \mathrm{KCl}, \mathrm{NaCl}, \mathrm{HCl}$, or $\mathrm{NaOH}$. Desorption was carried out by shaking the $\mathrm{Rb}$-saturated $\mathrm{KCoFC}$ with $50 \mathrm{~mL}$ of the reagents in a flat shaker at a shaking speed of $120 \mathrm{rpm}$ for $30 \mathrm{~min}$. The desorbed solutions were analysed for Rb concentration with MP-AES.

\section{Results and discussion}

\subsection{Characteristics of $\mathrm{KCoFC}$}

\subsubsection{Chemical decomposition analysis}

The chemical decomposition analysis showed that both $\mathrm{KCoFC}(\mathrm{L})$ and $\mathrm{KCoFC}(\mathrm{C})$ had reasonably similar chemical composition (Table 1). For $\mathrm{KCoFC}(\mathrm{L})$, the $\mathrm{K} / \mathrm{Fe}$ atomic ratio was 2.4 and $\mathrm{Co} / \mathrm{Fe}$ atomic ratio was 1.6 , while the corresponding ratios were 2.3 and 1.8 , for $\mathrm{KCoFC}(\mathrm{C})$. Previous studies have reported a similar composition for hexacyanoferrate sorbents $[19,22]$. For instance, Mardan et al. [22] found the stoichiometric composition of a potassium cobalt hexacyanoferrate to be $\mathrm{K}_{2 .{ }_{2}} \mathrm{Co}_{1.74} \mathrm{Fe}(\mathrm{CN})_{6}$. 
Table 1. Chemical composition of $\mathrm{KCoFC}$

\begin{tabular}{|c|c|c|c|c|c|c|c|}
\hline & & \multicolumn{3}{|c|}{ Before $\mathrm{Rb}$ sorption } & \multicolumn{3}{|c|}{ After $\mathrm{Rb}$ sorption } \\
\hline & & $\mathrm{K}$ & $\mathrm{Fe}$ & Co & $\mathrm{K}$ & $\mathrm{Fe}$ & Co \\
\hline \multirow[t]{3}{*}{$\mathrm{KCoFC}(\mathrm{L})$} & $\mathrm{mg} / \mathrm{g}$ & $127.8 \pm 3.1$ & $77.1 \pm 4.1$ & $130.3 \pm 2.3$ & $69.3 \pm 2.7$ & $71.3 \pm 3.2$ & $114.4 \pm 5.4$ \\
\hline & $\mathrm{wt} \%$ & 12.8 & 7.7 & 13.0 & 6.9 & 7.1 & 11.4 \\
\hline & $\mathrm{mmol} / \mathrm{g}$ & 3.3 & 1.4 & 2.2 & 1.8 & 1.4 & 1.9 \\
\hline \multirow[t]{3}{*}{$\mathrm{KCoFC}(\mathrm{C})$} & $\mathrm{mg} / \mathrm{g}$ & $137.4 \pm 2.3$ & $85.8 \pm 3.1$ & $157.7 \pm 0.9$ & $69.6 \pm 3.7$ & $83.3 \pm 2.3$ & $128.7 \pm 1.5$ \\
\hline & $\mathrm{wt} \%$ & 13.7 & 8.6 & 15.8 & 7.0 & 8.3 & 12.9 \\
\hline & $\mathrm{mmol} / \mathrm{g}$ & 3.5 & 1.5 & 2.7 & 1.8 & 1.5 & 2.2 \\
\hline
\end{tabular}

\subsubsection{SEM-EDX analysis}

The SEM images showed that $\mathrm{KCoFC}(\mathrm{L})$ and $\mathrm{KCoFC}(\mathrm{C})$ had a similar appearance, i.e. a porous and rough morphology before Rb sorption (Fig. 1a). After Rb sorption, no significant morphological changes were observed on the KCoFC sorbents (Fig. 1b).

The EDX emission pattern revealed the presence of $\mathrm{K}, \mathrm{Fe}$, and Co peaks in the samples representing the main metals of the $\mathrm{KCoFC}$. The semi-qualitative element analysis showed that for $\mathrm{KCoFC}(\mathrm{L})$, the atomic ratio for $\mathrm{K} / \mathrm{Fe}$ was 1.2 while for $\mathrm{Co} / \mathrm{Fe}$ it was 1.4 . Similarly, for $\mathrm{KCoFC}(\mathrm{C})$, the corresponding ratios were 1.0 and 1.5, respectively. Both the EDX and chemical decomposition analysis indicated a good match for the atomic ratio of $\mathrm{Co} / \mathrm{Fe}$ (1.4 and 1.5 for EDX vs 1.6 and 1.8 for chemical decomposition). On the other hand, the K/Fe ratio for the EDX analysis was much lower (K/Fe 1.0-1.2) compared to the chemical decomposition analysis (K/Fe 2.4). This could be due to the limitation of EDX emission in capturing $\mathrm{K}$ that is located in the body/centre of the cubic caged $\mathrm{KCoFC}$ structure, in comparison to $\mathrm{Fe}$ and Co which are primarily located at the corners of the structure [23]. The low $\mathrm{K} / \mathrm{Fe}$ atomic ratio of $1.0-1.2$ 
obtained was consistent with a recent study reporting a $\mathrm{K} / \mathrm{Fe}$ atomic ratio of 1.23 for potassium nickel hexacyanoferrate using EDX analysis [24].

Upon $\mathrm{Rb}$ sorption, a peak of $\mathrm{Rb}$ in the energy zone of $1.7 \mathrm{keV}$ was observed in the EDX spectra with a reduction of $\mathrm{K}$ peak intensity, suggesting the sorption of $\mathrm{Rb}$ with the exchange of $\mathrm{K}$ (Fig. 1b). Consistent with this, for both $\mathrm{KCoFC}(\mathrm{C})$ and $\mathrm{KCoFC}(\mathrm{L})$ a slight reduction in $\mathrm{K} / \mathrm{Fe}$ ratio was detected following $\mathrm{Rb}$ sorption while no difference was observed for the $\mathrm{Co} / \mathrm{Fe}$ ratio. The chemical composition analysis (Table 1) was able to show a clear reduction of $\mathrm{K} / \mathrm{Fe}$ ratio upon $\mathrm{Rb}$ sorption from $2.3-2.4$ to $1.2-1.3$ with minimal change of $\mathrm{Co} / \mathrm{Fe}$. 
(a)

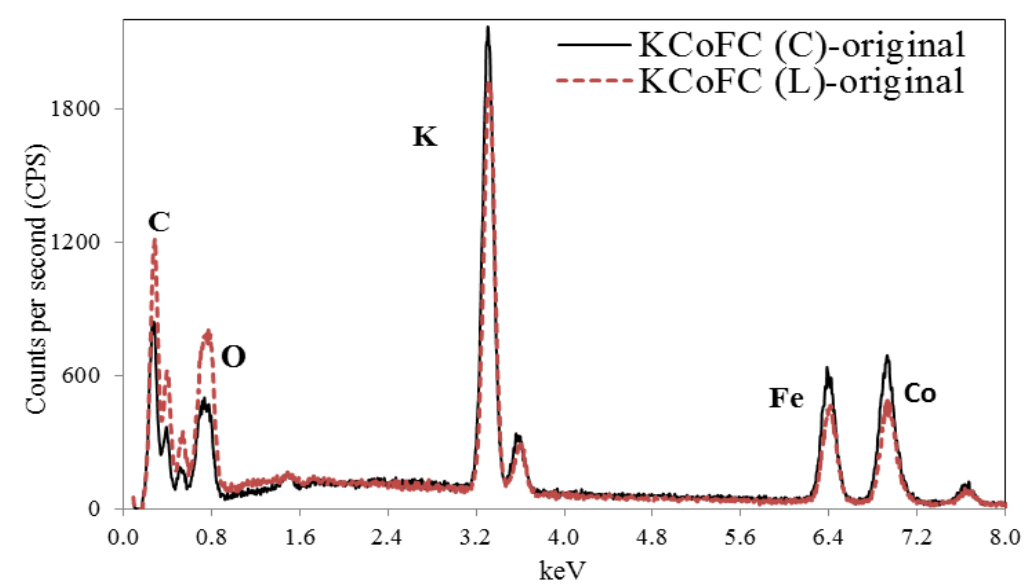

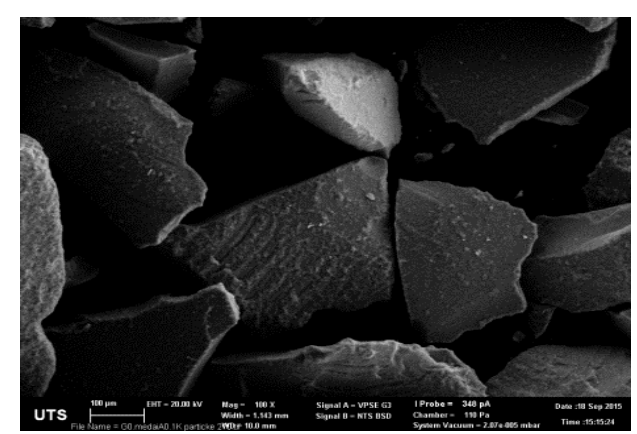

$\mathrm{KCoFC}(\mathrm{C})$

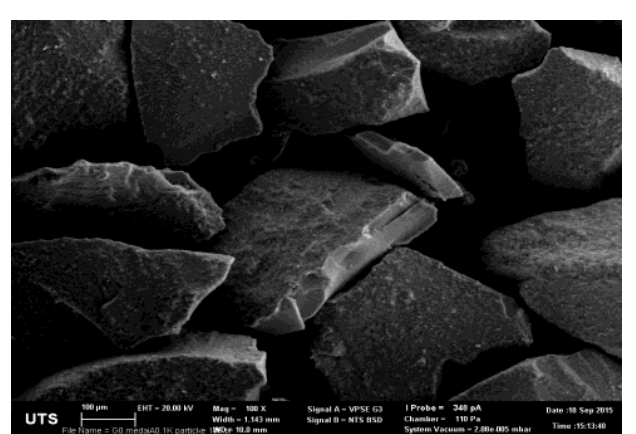

$\operatorname{KCoFC}(\mathbf{L})$

(b)

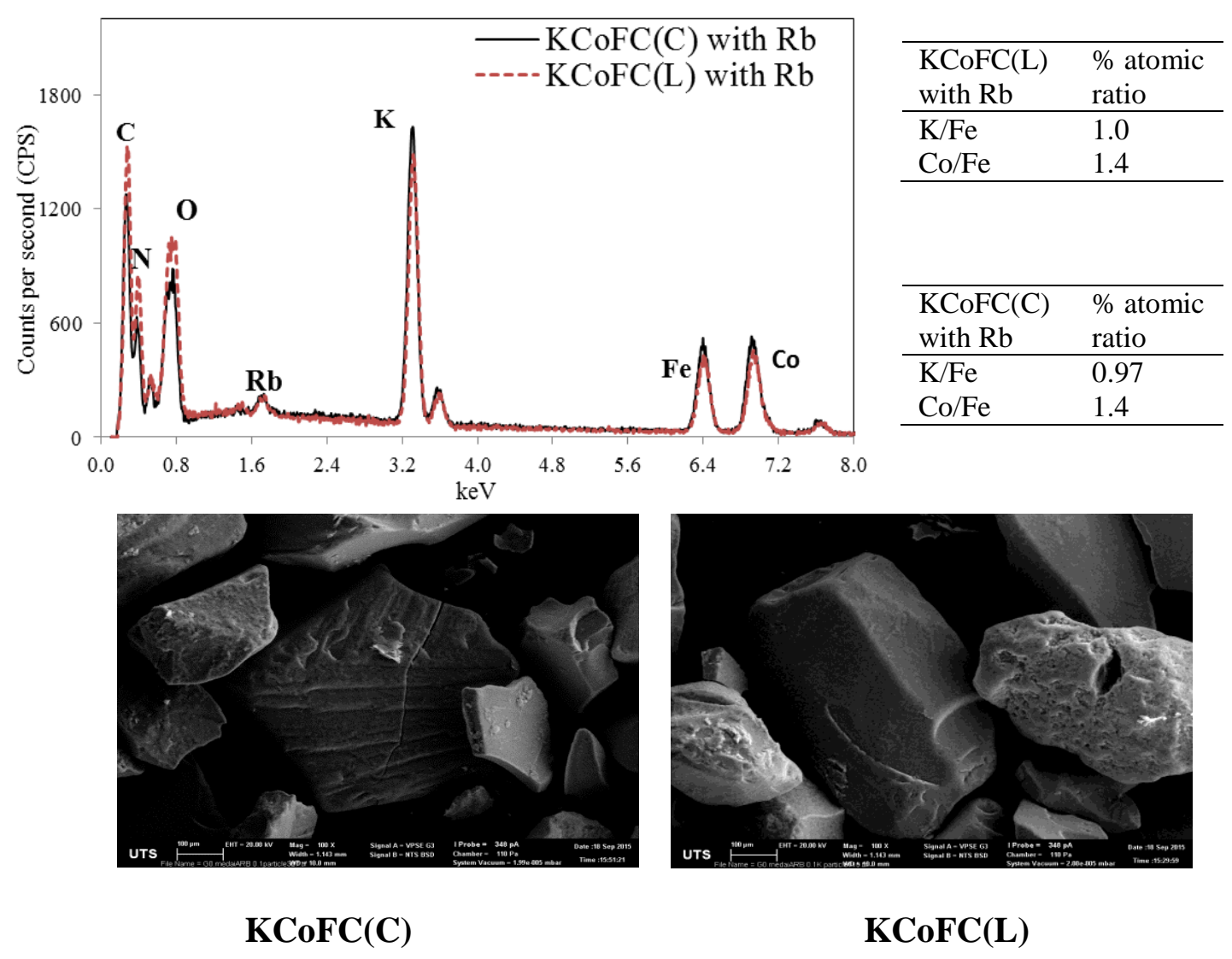

Fig. 1. SEM-EDS analysis of $\mathrm{KCoFC}(\mathrm{C})$ and $\mathrm{KCoFC}(\mathrm{L})$ (a) original (b) after $\mathrm{Rb}$ sorption. 


\subsubsection{Powder X-ray diffraction (XRD) analysis}

The XRD composition showed the same diffraction peaks for both the lab and commercial sorbent, confirming the similarity in crystal structure (Fig. 2). In this respect, previous studies on $\mathrm{KCoFC}$ sorbent, reported that main diffraction lines for $\mathrm{KCoFC}$ to be $2 \theta=$ $17.72,25.24,36.08,40.56,42.8,52.2$ and $58.64^{\circ}[12,25]$. The corresponding sharp peaks were detected in this XDR analysis, verifying the positions of the main diffraction lines for both $\mathrm{KCoFC}(\mathrm{C})$ and $\mathrm{KCoFC}(\mathrm{L})$.

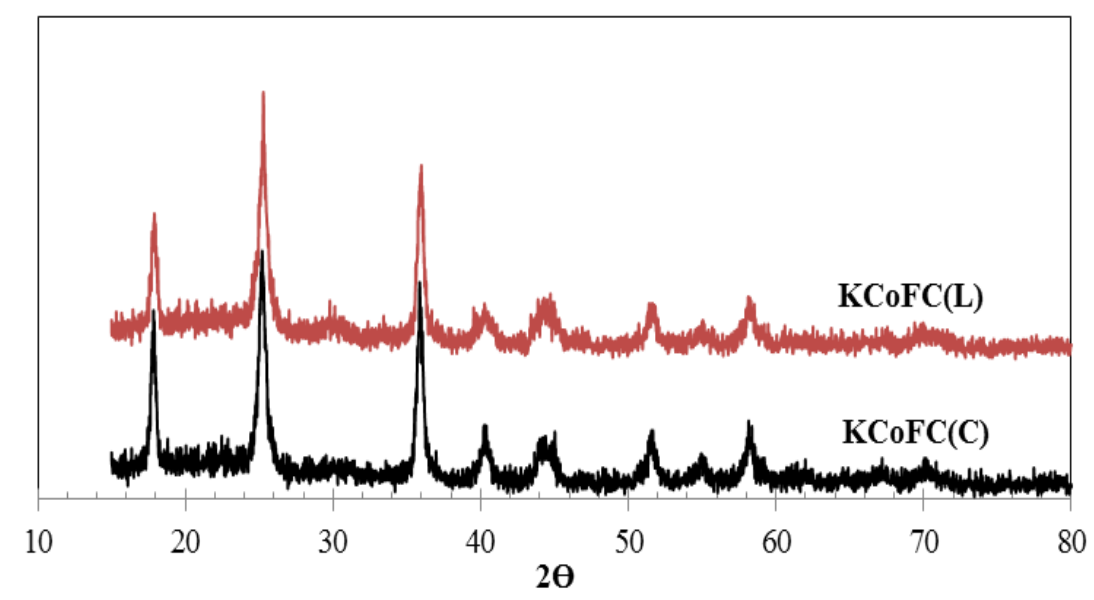

Fig. 2. XRD peaks of $\mathrm{KCOFC}(\mathrm{L})$ and $\mathrm{KCoFC}(\mathrm{C})$.

\subsubsection{Surface area and pore volume}

The surface area of $\mathrm{KCoFC}(\mathrm{L})$ was $55.4 \mathrm{~m}^{2} / \mathrm{g}$ with a total pore volume of $0.26 \mathrm{~cm}^{3} / \mathrm{g}$ while the average pore diameter was $18.8 \mathrm{~nm}$. On the other hand, $\mathrm{KCoFC}(\mathrm{C})$ showed higher values for all these parameters (surface area $72.1 \mathrm{~m}^{2} / \mathrm{g}$, total pore volume $0.37 \mathrm{~cm}^{3} / \mathrm{g}$, pore diameter $20.5 \mathrm{~nm}$ ) in comparison to $\mathrm{KCoFC}(\mathrm{L})$. This could be attributed to the difference in mixing and drying of the sorbent during commercial production. The respective average pore diameters of 18.8 and $20.5 \mathrm{~nm}$ for the two $\mathrm{KCoFC}$ indicate that these materials consist mainly of mesopores $(2-50 \mathrm{~nm})$. 


\subsection{Influence of $p H$ on the sorption of $R b$}

The $\mathrm{pH}$ of the aqueous solution is an important controlling parameter in the sorption process because it influences the surface charge on the sorbent. To study the influence of $\mathrm{pH}$, experiments were conducted between $\mathrm{pH} 3$ to 10 . $\mathrm{Rb}$ sorption capacity increased up to $\mathrm{pH} 7$ 8 and then declined as $\mathrm{pH}$ increased (Fig. 3). The maximum sorption capacity of Rb was achieved at a $\mathrm{pH}$ range of 7 to 8 .

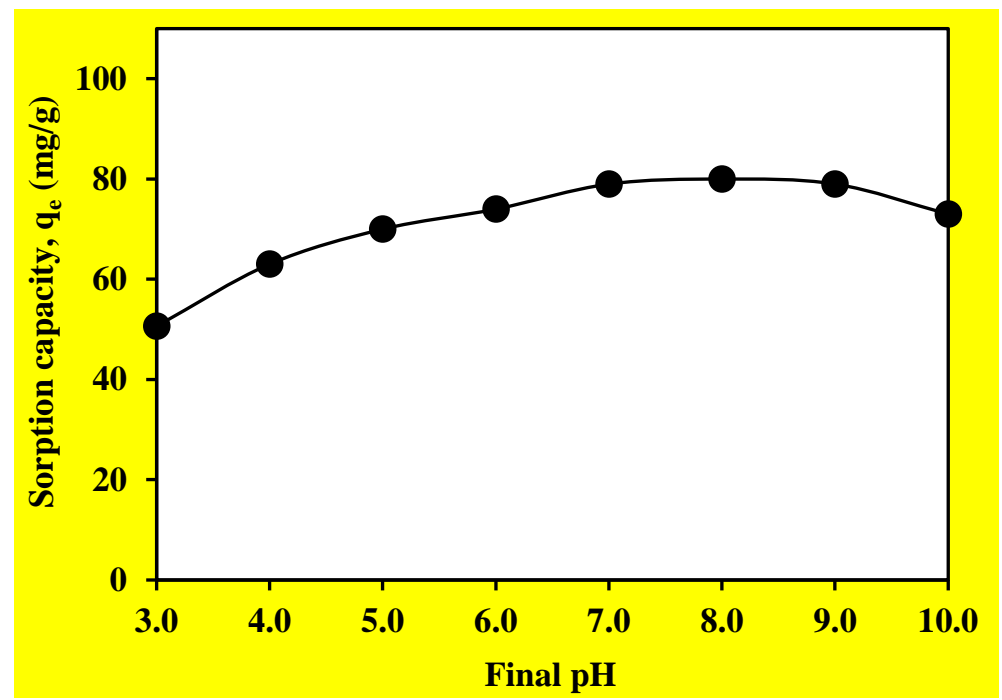

Fig. 3. Influence of $\mathrm{pH}$ on $\mathrm{Rb}$ sorption $\left(\mathrm{C}_{\mathrm{o}}=5 \mathrm{mg} / \mathrm{L}, \mathrm{KCoFC}\right.$ dosage $\left.=0.05 \mathrm{mg} / \mathrm{L}\right)$.

The increased sorption was mainly due to an increase in the negative surface charge on the sorbent as indicated by the zeta potential trend (Fig. 4). Increased negative charge on the sorbent is expected to increase the sorption of positively charged ions such as $\mathrm{Rb}$ by electrostatic adsorption (outer sphere complexation). The lower $\mathrm{Rb}$ sorption at low $\mathrm{pH}$ is also due to the competition of $\mathrm{H}$ with $\mathrm{Rb}$ for sorption sites in the highly acidic solution where the concentration of $\mathrm{H}$ is high. At high $\mathrm{pH}$ (above 8), the presence of increased concentration of $\mathrm{Na}$ (arising from $\mathrm{pH}$ adjustment with $\mathrm{NaOH}$ ) most likely competed with $\mathrm{Rb}$ sorption, thus reducing $\mathrm{Rb}$ sorption capacity. Since the maximum sorption capacity of $\mathrm{Rb}$ was obtained at a final $\mathrm{pH}$ range of 7 to 8 , all further experiments were carried out at $\mathrm{pH} 7.0 \pm 0.5$. 


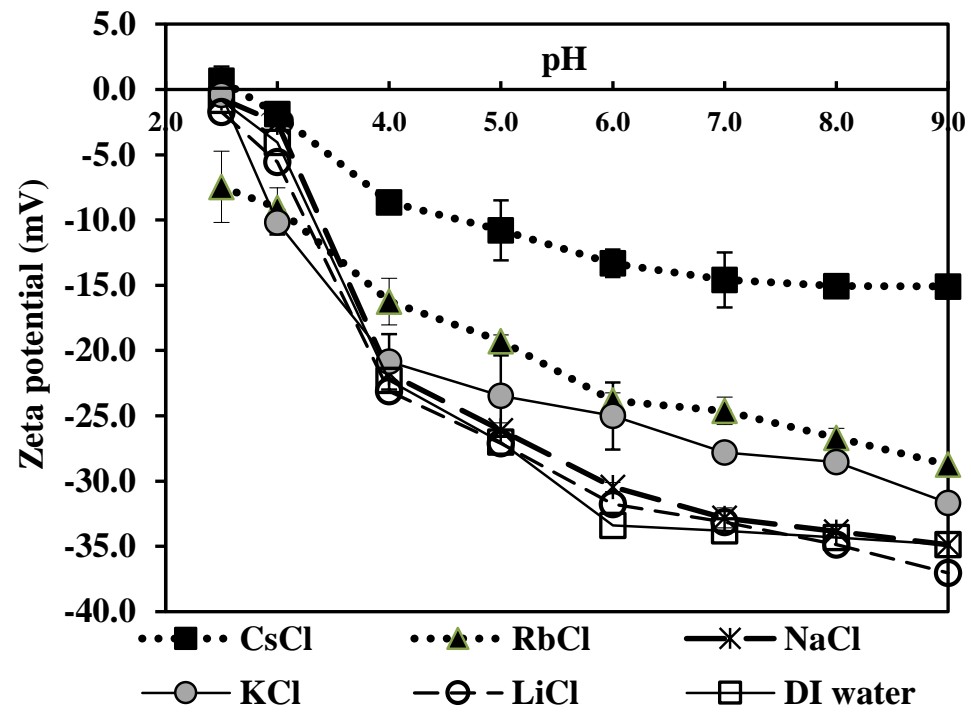

Fig. 4. Zeta potential trend as a function of $\mathrm{pH}$ for alkali metals $\left(1 \times 10^{-4} \mathrm{M}\right)$ and DI water $(\mathrm{KCoFC}$ dosage $=0.1 \mathrm{~g} / \mathrm{L})$. 
Table 2. Hydrated and unhydrated ionic radius of alkali metals

\begin{tabular}{lll}
\hline Alkali metal & Hydrated ionic radius, $\AA$ [5] & Unhydrated ionic radius, $\AA$ [23] \\
\hline $\mathrm{Cs}$ & $2.26-2.28$ & 1.68 \\
$\mathrm{Rb}$ & 2.28 & 1.48 \\
$\mathrm{~K}$ & $2.32-3.31$ & 1.33 \\
$\mathrm{Na}$ & $2.76-3.60$ & 0.95 \\
$\mathrm{Li}$ & $3.40-4.70$ & 0.60 \\
\hline
\end{tabular}

\section{3. $\quad R b$ and Cs sorption capacity}

Both $\mathrm{KCoFC}(\mathrm{L})$ and $\mathrm{KCoFC}(\mathrm{C})$ sorbents showed much higher sorption capacity for $\mathrm{Rb}$ and $\mathrm{Cs}$ than $\mathrm{Li}, \mathrm{Na}$ and $\mathrm{Ca}$ at all equilibrium solution concentration of the metals (Fig. 5). As both $\mathrm{KCoFC}(\mathrm{C})$ and $\mathrm{KCoFC}(\mathrm{L})$ sorbents showed similar characteristics (SEM-EDX, chemical composition, XRD), a similar sorption capacity would be expected for both sorbents. However, a slightly higher sorption capacity was observed with $\mathrm{KCoFC}(\mathrm{C})$ compared to $\mathrm{KCoFC}(\mathrm{L})$. This could be attributed to the higher surface area and pore volume of the $\mathrm{KCoFC}(\mathrm{C})$.

The sorption data were modelled using Langmuir and Freundlich equations. The sorption data for $\mathrm{Li}, \mathrm{Na}$, and $\mathrm{Ca}$ did not satisfactorily fit to these models. However, the data for $\mathrm{Rb}$ and $\mathrm{Cs}$ fitted well to both the models with the fit being better for the Langmuir model $\left(\mathrm{R}^{2}\right.$ $=0.92$ to 0.98$)$ than for the Freundlich model $\left(\mathrm{R}^{2}=0.73\right.$ to 0.93$)($ Fig. 5, Table 3). Similar observations were reported by Petersková et al. [5] for Rb and Cs sorption on potassium hexacyanoferrate sorbent. 


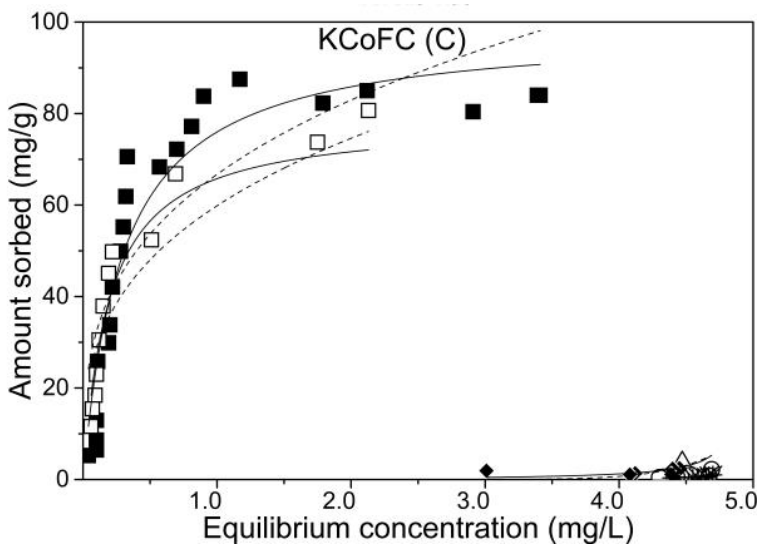

(a)

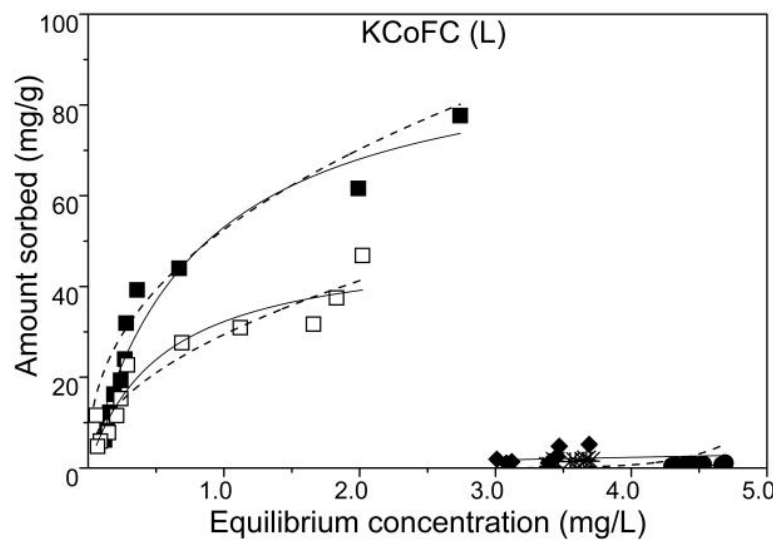

(b)

Fig. 5. Sorption capacity of (a) $\mathrm{KCoFC}(\mathrm{C})$ (b) $\mathrm{KCoFC}(\mathrm{L})$ with $\mathrm{Rb}(\boldsymbol{\square}), \mathrm{Cs}(\square), \mathrm{Na}(\boldsymbol{\bullet}), \mathrm{Li}$

$(\diamond)$ and $\mathrm{Ca}(*)$ ( — Langmuir model; ----- Freundlich model $)\left(\mathrm{C}_{\mathrm{o}}\right.$ of $\mathrm{Rb}$ and $\mathrm{Cs}=5 \mathrm{mg} / \mathrm{L}$, $\mathrm{C}_{\mathrm{o}}$ of $\mathrm{Ca}, \mathrm{Na}$ and $\mathrm{Li}=20 \mathrm{mg} / \mathrm{L}$, final $\left.\mathrm{pH} 7 \pm 0.5\right)$.

Table 3. Langmuir and Freundlich models parameters at final $\mathrm{pH} 7.0 \pm 0.5$.

\begin{tabular}{|c|c|c|c|c|c|c|c|}
\hline \multirow[t]{2}{*}{ Metal } & \multirow[t]{2}{*}{ Sorbent } & \multicolumn{3}{|c|}{ Langmuir } & \multicolumn{3}{|c|}{ Freundlich } \\
\hline & & $\begin{array}{l}\mathrm{Q}_{\max } \\
(\mathrm{mg} / \mathrm{g})\end{array}$ & $\begin{array}{l}\mathrm{K}_{\mathrm{L}} \\
(\mathrm{L} / \mathrm{r}\end{array}$ & $\mathrm{R}^{2}$ & $\mathrm{n}$ & $\begin{array}{l}\mathrm{K}_{\mathrm{F}} \\
(\mathrm{mg} / \mathrm{q}\end{array}$ & $\mathrm{R}^{2}$ \\
\hline \multirow[t]{2}{*}{$\mathrm{Rb}$} & $\mathrm{KCoFC}(\mathrm{C})$ & 100.1 & 3.7 & 0.98 & 1.7 & 71.4 & 0.86 \\
\hline & $\mathrm{KCoFC}(\mathrm{L})$ & 96.2 & 1.2 & 0.95 & 1.8 & 48.2 & 0.86 \\
\hline \multirow[t]{2}{*}{$\mathrm{Cs}$} & $\mathrm{KCoFC}(\mathrm{C})$ & 75.8 & 5.9 & 0.92 & 2.6 & 62.6 & 0.73 \\
\hline & $\mathrm{KCoFC}(\mathrm{L})$ & 60.9 & 1.0 & 0.96 & 1.5 & 32.2 & 0.93 \\
\hline
\end{tabular}

In the Langmuir model, the value of $R_{L}$ as calculated from the formula, $R_{L}=1 /\left(1+C_{m}\right.$ $\mathrm{K}_{\mathrm{L}}$ ) (where $\mathrm{C}_{\mathrm{m}}$ is the maximum initial concentration of sorbate), indicates the favourability of the sorption process, such as unfavourable $\left(\mathrm{R}_{\mathrm{L}}>1\right)$, favourable $\left(0<\mathrm{R}_{\mathrm{L}}<1\right)$ or irreversible $\left(\mathrm{R}_{\mathrm{L}}\right.$ 
$=0)$ [20]. The calculated $\mathrm{R}_{\mathrm{L}}$ values for $\mathrm{Rb}$ and $\mathrm{Cs}$ data were in the 0.04 to 0.25 range, indicating that the sorption process is favourable for both these metals.

Langmuir model fits to data showed that for $\mathrm{Rb}$, a $\mathrm{Q}_{\max }$ of 96.2 to $100.1 \mathrm{mg} / \mathrm{g}$ (1.13.to $1.17 \mathrm{mmole} / \mathrm{g}$ ) was achieved for both the lab and commercial KCoFC. Comparatively, a lower $\mathrm{Q}_{\max }$ was achieved for Cs at 60.9 to $75.8 \mathrm{mg} / \mathrm{g}$ (0.46 to $0.57 \mathrm{mmole} / \mathrm{g}$ ) (Table 3). Previous studies on $\mathrm{Rb}$ and $\mathrm{Cs}$ sorption with commercial $\mathrm{KCoFC}$ (CsTreat) reported a similar pattern of relatively higher $\mathrm{Rb}$ sorption compared to Cs sorption [5,6,23]. For instance, Petersková et al. [5] reported a $\mathrm{Q}_{\max }$ of $46.73 \mathrm{mg} / \mathrm{g}$ for $\mathrm{Rb}$ sorption and a $\mathrm{Q}_{\max }$ of $32.36 \mathrm{mg} / \mathrm{g}$ for Cs sorption with a commercial $\mathrm{KCoFC}$ at $\mathrm{pH} 7.8$ and equilibrium metal concentrations of $5-80 \mathrm{mg} / \mathrm{L}$.

The capacity of alkali metal sorption on sorbents is generally in the order of $\mathrm{Cs}>\mathrm{Rb}>$ $\mathrm{K}>\mathrm{Na}>\mathrm{Li}$ based on the hydrated radius of the ions (Table 2). The smaller the hydrated ionic radius, the closer the ion can reach the sorbent surface, and therefore the stronger the sorption. Based on the hydrated ionic radius, Cs should exhibit similar or higher sorption capacity compared to $\mathrm{Rb}$. Conversely, a relatively higher sorption of $\mathrm{Rb}$ was observed in this study as well as in previous research. Lehto et al. [23] associated this phenomenon to the similar sizes of the KCoFC cavities within the lattice $(1.47 \AA)$ and the unhydrated $\mathrm{Rb}$ radius $(1.48 \AA)$ compared to the larger unhydrated Cs radius $(1.61 \AA)$. Therefore, Rb was able to achieve a higher penetration into the crystal lattices, displacing the $\mathrm{K}$ in the lattices, hence exhibiting a higher sorption capacity.

The occurrence of lattice ion exchange was evident as $\mathrm{K}$ was released with the sorption of $\mathrm{Rb}$ and $\mathrm{Cs}$ (Table 4). At equilibrium, the corresponding amount of $\mathrm{K}$ released was higher for $\mathrm{Rb}$ than for $\mathrm{Cs}$, confirming the higher penetration of $\mathrm{Rb}$ into the $\mathrm{KCoFC}$ crystal lattice. Prout et al. [18] described this exchange reaction utilising the following equation: 
It is important to highlight that an additional amount of $\mathrm{K}$ release was detected (1.05$1.39 \mathrm{mmol} / \mathrm{g}$ ) relative to the amount of $\mathrm{Cs}$ and $\mathrm{Rb}$ sorbed (Table 4). Previous studies related the excess fraction of $\mathrm{K}$ released to the dissolution of $\mathrm{K}$ from the sorbent in aqueous solution [23]. In line with this, the blank test with DI water showed $0.40 \pm 0.19 \mathrm{mmol} / \mathrm{g} \mathrm{K}$ release (Table 4). Upon subtracting the soluble $\mathrm{K}$ released from the total amount of $\mathrm{K}$ released when $\mathrm{Rb}$ and Cs were sorbed, the ratios of $\mathrm{Rb}$ and $\mathrm{Cs}$ sorbed to $\mathrm{K}$ released (mmoles) were 0.92 and 1.09, respectively. This indicates that there was stoichiometric electrochemical balance in the exchange process.

Table 4. Alkali metals sorption on $\mathrm{KCoFC}(\mathrm{L})$ and the corresponding amounts of $\mathrm{K}$, Co and Fe released

\begin{tabular}{llllll}
\hline $\begin{array}{l}\text { Alkali } \\
\text { metal }\end{array}$ & $\begin{array}{l}\text { Equilibrium metal } \\
\text { concentration }(\mathrm{mg} / \mathrm{L})\end{array}$ & $\begin{array}{l}\text { Metal sorbed } \\
(\mathrm{mmol} / \mathrm{g})\end{array}$ & $\begin{array}{l}\text { K released } \\
(\mathrm{mmol} / \mathrm{g})\end{array}$ & $\begin{array}{l}\text { Co released } \\
(\mathrm{mmol} / \mathrm{g})\end{array}$ & $\begin{array}{l}\text { Fe released } \\
(\mathrm{mmol} / \mathrm{g})\end{array}$ \\
\hline $\mathrm{Rb}$ & 2.74 & $0.91 \pm 0.11$ & $1.39 \pm 0.25$ & $0.07 \pm 0.05$ & $0.05 \pm 0.02$ \\
$\mathrm{Cs}$ & 2.92 & $0.71 \pm 0.09$ & $1.05 \pm 0.42$ & $0.05 \pm 0.02$ & $0.04 \pm 0.02$ \\
$\mathrm{Na}$ & 4.81 & $0.14 \pm 0.09$ & $0.51 \pm 0.38$ & $0.06 \pm 0.03$ & $0.05 \pm 0.01$ \\
$\mathrm{Li}$ & 3.01 & $0.17 \pm 0.08$ & $0.58 \pm 0.29$ & $0.04 \pm 0.02$ & $0.05 \pm 0.02$ \\
& & & & & \\
$\mathrm{DI}$ (blank) & & - & $0.40 \pm 0.19$ & $0.02 \pm 0.03$ & $0.03 \pm 0.01$
\end{tabular}

During the $\mathrm{Rb}$ and $\mathrm{Cs}$ sorption process very little $\mathrm{Co}$ and $\mathrm{Fe}$ were released, which indicated that $\mathrm{Rb}$ and $\mathrm{Cs}$ were not exchanging with $\mathrm{Co}$ and $\mathrm{Fe}$ in the crystal lattice (Table 4). This is because $\mathrm{Co}$ and $\mathrm{Fe}$ are transitional metal cations bridged through cyano $(\mathrm{CN})$ groups in the lattice structure which cannot be exchanged with the alkali metals Rb and Cs [26]. Loos- 
Neskovic et al. [26] reported that the cyano groups bridged to $\mathrm{Fe}$ and $\mathrm{Cu}$ in $\mathrm{K}_{2}\left[\mathrm{CuFe}(\mathrm{CN})_{6}\right]$ provided negative charges which were balanced by the positively charged $\mathrm{K}$ in the body centre of the lattice.

\subsubsection{KCoFC sorption capacity with other alkali metals}

While $\mathrm{Rb}$ and $\mathrm{Cs}$ exhibited high sorption capacity on $\mathrm{KCoFC}$, other metals such as $\mathrm{Li}$, $\mathrm{Na}$ and $\mathrm{Ca}$ remained mostly unchanged in the initial solutions without having any appreciable sorption (Fig. 5). The difference in the sorptivity between the metals can be explained on the basis of the relative size of the target ions and the pores or cavities of the sorbent as presented in Table 2. The amounts of $\mathrm{Na}$ and $\mathrm{Li}$ sorbed were much lower than those of $\mathrm{Rb}$ and $\mathrm{Cs}$ because of their lower degree of ion exchange with lattice $\mathrm{K}$ as seen from the smaller amounts of $\mathrm{K}$ released when they were sorbed (Table 4). This lower degree of ion exchange is due to the smaller unhydrated ionic radius of $\mathrm{Na}$ and $\mathrm{Li}$ (Table 2). Most of the $\mathrm{K}$ released during the sorption of $\mathrm{Li}$ and $\mathrm{Na}$ was due to the release of water soluble $\mathrm{K}$ in the sorbent. Another reason for the lower sorption of $\mathrm{Li}$ and $\mathrm{Na}$ than $\mathrm{Rb}$ and $\mathrm{Cs}$ is that these metals were more strongly hydrated and therefore bind more weakly to the KCoFC surface (Table 2). The zeta potential data on $\mathrm{KCoFC}$ supports this surface sorption difference between the metals. The negative zeta potential in the presence of monovalent metals increased in the order of the degree of ion hydration $(\mathrm{Li}>\mathrm{Na}>\mathrm{K}>\mathrm{Rb}>\mathrm{Cs})$ (Fig. 4). The less hydrated monovalent cations ( $\mathrm{Rb}, \mathrm{Cs})$ bind more strongly to the KCoFC surface resulting in relatively lower negativity of the zeta potential (-12 to -23 compared to -27 to -33 for $\mathrm{Li}, \mathrm{Na}, \mathrm{K}$ at $\mathrm{pH} 7$ ).

\section{4. $\quad R b$ sorption kinetics}

Kinetics of sorption governs the uptake rate of sorbates and is therefore an important aspect in assessing the sorbent's characteristics. The kinetic results of $\mathrm{KCoFC}(\mathrm{L})$ displayed an 
increased sorption capacity of $\mathrm{Rb}$ with contact time (Fig. 6). A maximum sorption of around $63 \%$ was achieved within $15 \mathrm{~h}$. In correspondence with the sorption of $\mathrm{Rb}, \mathrm{K}$ release was detected over the entire duration of sorption (Fig. 6). The number of mmoles of $\mathrm{K}$ released at any time was equivalent to the number of moles of $\mathrm{Rb}$ sorbed (additional $\mathrm{K}$ released from sorbent dissociation in aqueous solution was offset by the blank DI correction as presented in Table 4). The majority of $\mathrm{K}$ released occurred when $\mathrm{Rb}$ exchanged with $\mathrm{K}$ inside the $\mathrm{KCoFC}$ lattice.

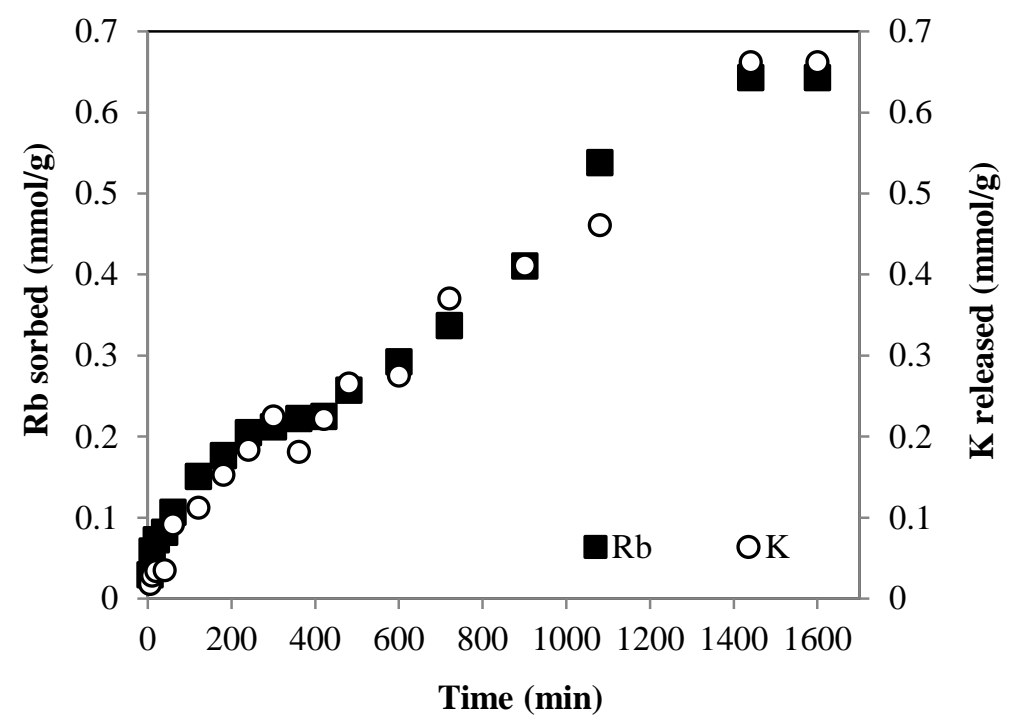

Fig. 6. $\mathrm{Rb}$ sorbed and $\mathrm{K}$ released as a function of time $\left(\mathrm{C}_{\mathrm{o}}=5 \mathrm{mg} / \mathrm{L}, \mathrm{KCoFC}\right.$ dosage $=0.05$ $\mathrm{g} / \mathrm{L}, \mathrm{pH} 7)$.

The sorption kinetics data was analysed using different kinetic models. The results showed that the data fitted slightly better to PSO model than to PFO model with $\mathrm{R}^{2}$ values of 0.97 and 0.92, respectively (Fig. 7). Furthermore, for the PFO model, the $\mathrm{q}_{\mathrm{e}}$ value of $63.4 \mathrm{mg} / \mathrm{g}$ derived from the model differed from the experimental $\mathrm{q}_{\mathrm{e}}$ value of $56.6 \mathrm{mg} / \mathrm{g}$. On the other hand, for the PSO model, the $\mathrm{q}_{\mathrm{e}}$ value of $55.5 \mathrm{mg} / \mathrm{g}$ derived from the model agreed better with the experimental value. Therefore the kinetics data is better described by the PSO model. Better 
description of the data by PSO suggested that the sorption of $\mathrm{Rb}$ is mainly controlled by chemical process [20] which depends on the concentration of $\mathrm{Rb}$ in solution and the number of sorption sites on KCoFC that were unoccupied by $\mathrm{Rb}$.

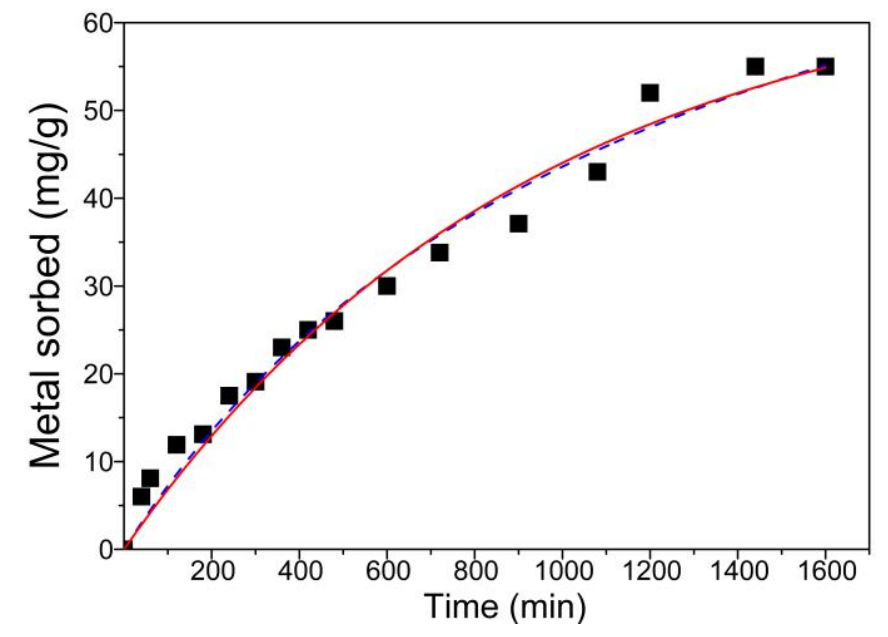

Fig.7. Kinetic model fit for experimental data of $\mathrm{Rb}$ sorption on $\mathrm{KCoFC}(\mathrm{L})(\mathrm{Rb}$ experimental data (घ), - PFO; -----PSO) $\left(\mathrm{C}_{\mathrm{o}}=5 \mathrm{mg} / \mathrm{L}, \mathrm{KCoFC}\right.$ dose $\left.0.05 \mathrm{~g} / \mathrm{L}, \mathrm{pH} 7\right)$.

Generally, kinetic models describe the whole sorption process but the actual rate limiting steps are not provided in detail. The transportation of $\mathrm{Rb}$ from the bulk solution to the KCoFC surface can be described by: (1) bulk diffusion from the external solution to the film surrounding the KCoFC particle (bulk diffusion) (2) diffusion of $\mathrm{Rb}$ through the film surrounding the KCoFC particles (film diffusion); (3) diffusion of $\mathrm{Rb}$ through the hydrated pores of the KCoFC particle (intraparticle diffusion); and (4) chemical exchange reaction of $\mathrm{Rb}$ at the internal particle surface and exchange with structural $\mathrm{K}$ (chemical reaction). Bulk diffusion is negligible in determining the limiting rate because of enough agitation in batch experiments which does not allow any concentration gradients to build-up. Intraparticle diffusion is highly likely because the particles are mesoporous. In this study, the Weber and Morris intraparticle diffusion model was used to represent the intraparticle diffusion trend with 
time for KCoFC [20,21]. According to Weber and Morris [21], if intraparticle diffusion is the rate limiting step in the sorption process, the plot of $\mathrm{q}_{\mathrm{t}}$ versus $\mathrm{t}^{0.5}$ would be a straight line that passes through the origin. In this study, the experimental data showed two linear portions (Fig. 8). The first linear portion from $5 \mathrm{~min}$ up to $4 \mathrm{~h}$ can be attributed to the transport by intraparticle diffusion of $\mathrm{Rb}$ through the pores and channels This is followed by a slow step where $\mathrm{Rb}$ exchanged with the structural $\mathrm{K}$ that is located in the body/centre of the cubic caged $\mathrm{KCoFC}$ [Table 4, Fig. 6] and the reduced rate of intraparticle diffusion resulting from the low $\mathrm{Rb}$ concentration in solution [27]. As the entire plot was not linear and did not pass through the origin, film diffusion, intra-particle diffusion, and exchange with structural $\mathrm{K}$ appeared to have occurred simultaneously during the sorption process. However, as film diffusion is faster than intraparticle diffusion, it would have been mostly completed within the first 5 min before most of the intraparticle diffusion operated. Intraparticle diffusion and exchange of $\mathrm{Rb}$ with structural $\mathrm{K}$ appear to be the major rate controlling steps.

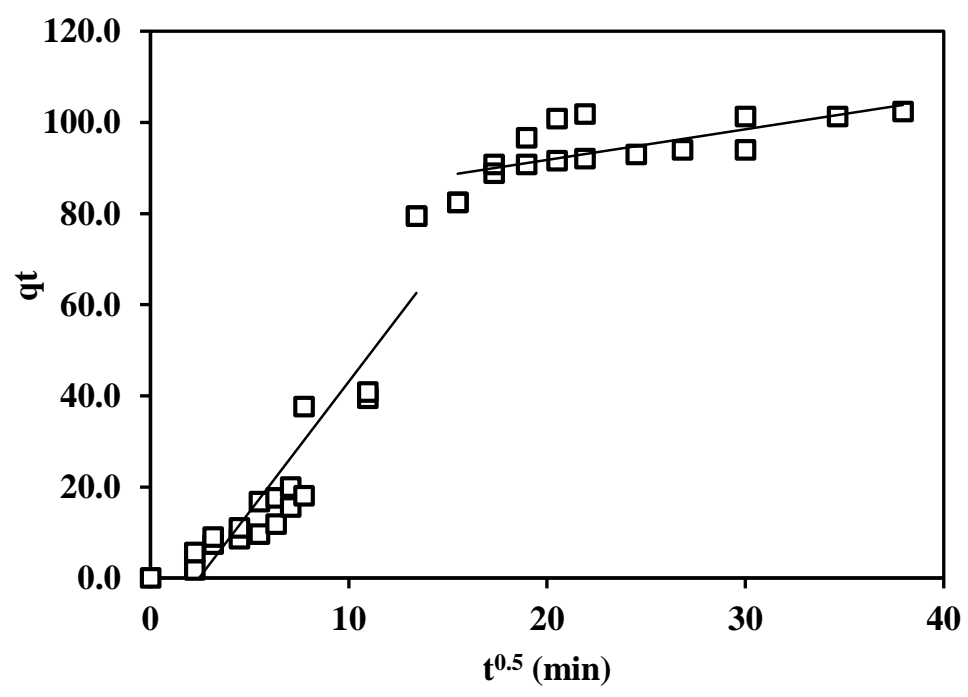

Fig. 8. Intraparticle diffusion kinetics of $\mathrm{Rb}\left(\mathrm{C}_{\mathrm{o}}=5 \mathrm{mg} / \mathrm{L}, \mathrm{KCoFC}\right.$ dose $\left.0.05 \mathrm{~g} / \mathrm{L}, \mathrm{pH} 7\right)$.

The results of the kinetic study clearly demonstrated that $\mathrm{Rb}$ was first adsorbed on to the surface of the $\mathrm{KCoFC}$ prior to the $\mathrm{K}$ ion exchange reaction within the crystal lattice as 
indicated by previous studies $[23,28]$. In line with this, as shown in the zeta potential trend (Fig. 4), the negativity of the surface potential/charge of KCoFC declined in the presence of $\mathrm{Rb}$, verifying the strong surface sorption of $\mathrm{Rb}$. At the same time, $\mathrm{K}$ was released over time when $\mathrm{Rb}$ was sorbed as shown in Fig. 6, confirming that ion exchange occurred between $\mathrm{Rb}$ in solution and $\mathrm{K}$ in the sorbent lattice.

\subsection{Effect of competing ions on $R b$ sorption}

An important factor that influences the performance of a sorbent for a target metal is the selective sorption of the metal in the presence of competitor ions. In order to verify the selectivity of $\mathrm{KCoFC}(\mathrm{L})$ for $\mathrm{Rb}$, the sorption capacity of $\mathrm{Rb}$ was evaluated in the presence of other competitor monovalent alkali metals $(\mathrm{Cs}, \mathrm{Li}, \mathrm{Na}, \mathrm{K})$ as well as the divalent metal, $\mathrm{Ca}$ at a range of concentrations (Fig. 9). All experiments were conducted with an initial $\mathrm{Rb}$ concentration of $5 \mathrm{mg} / \mathrm{L}$ and sorbent dosage of $0.05 \mathrm{~g} / \mathrm{L}$ while the competitor ions concentration increased from 5 to $20 \mathrm{mg} / \mathrm{L}$. 


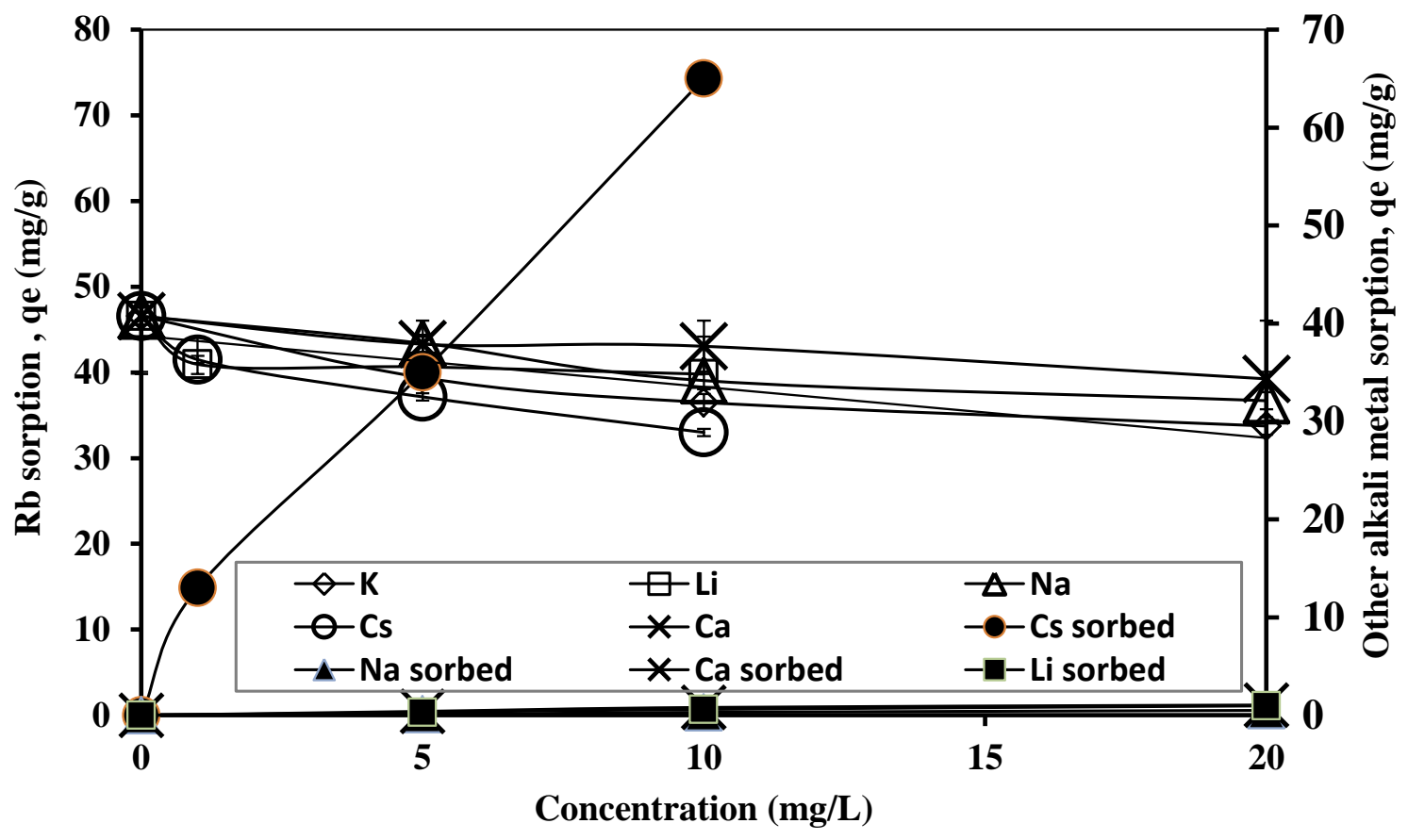

Fig. 9. Effect of coexisting alkali metals and $\mathrm{Ca}$ on $\mathrm{Rb}$ sorption on $\mathrm{KCoFC}(\mathrm{L})$ (KCoFC dose $0.05 \mathrm{~g} / \mathrm{L}$, initial $\mathrm{Rb}$ concentration $5 \mathrm{mg} / \mathrm{L}, \mathrm{pH}$ 7).

The results showed that when $\mathrm{Rb}$ and $\mathrm{Cs}$ were present together at the same concentration $(5 \mathrm{mg} / \mathrm{L})$, the individual $\mathrm{Rb}$ and $\mathrm{Cs}$ sorption capacities of $49.9 \mathrm{mg} / \mathrm{g}$ and 40.1 $\mathrm{mg} / \mathrm{g}$, decreased slightly by $7-12 \%$. This indicated that $\mathrm{KCoFC}$ has a high selectivity for both $\mathrm{Cs}$ and $\mathrm{Rb}$, and therefore was only slightly affected by each other's co-ion effect. Naturally, at higher $\mathrm{Cs}$ concentration $(10 \mathrm{mg} / \mathrm{L})$, the $\mathrm{Rb}$ sorption reduced further by $25-29 \%$. However, in many situations such as in seawater, the Cs concentration $(0.0005 \mathrm{mg} / \mathrm{L})$ is much lower than $\mathrm{Rb}$ concentration $(0.12 \mathrm{mg} / \mathrm{L})$ and therefore $\mathrm{Cs}$ is not expected to affect the sorption of $\mathrm{Rb}$ by $\mathrm{KCoFC}[6]$.

Comparatively, $\mathrm{Rb}$ sorption was minimally affected by the presence of alkali metals, $\mathrm{Li}, \mathrm{Na}$, and $\mathrm{K}$ and divalent alkaline earth metal, $\mathrm{Ca}$ at concentrations of 5 to $20 \mathrm{mg} / \mathrm{L}$ (Fig. 9). At a concentration of $20 \mathrm{mg} / \mathrm{L}$ of the other metals, the Rb sorption capacity was reduced only 
by $10-15 \%$ and the sorption of $\mathrm{Li}, \mathrm{Na}, \mathrm{K}$, and $\mathrm{Ca}$ was less than $2 \mathrm{mg} / \mathrm{g}$. Therefore, $\mathrm{Rb}$ sorption on $\mathrm{KCoFC}$ was only influenced by the presence of $\mathrm{Cs}$ at a higher concentration while the influence of other metals ( $\mathrm{Li}, \mathrm{Na}, \mathrm{K}, \mathrm{Ca})$ was minimal.

\section{6. $\quad R b$ desorption capacity}

At a concentration of $0.1 \mathrm{M}$ of desorption agent, the percentage of $\mathrm{Rb}$ desorption declined in the order of $\mathrm{KCl}(74.0 \%), \mathrm{KOH}(47.3 \%), \mathrm{NaOH}(46.5 \%), \mathrm{NaCl}(10.5 \%), \mathrm{HCl}$ (1.75\%), and $\mathrm{HNO}_{3}(0.75 \%)$ (Fig. 10). Percentage desorption with $\mathrm{H}_{2} \mathrm{O}$ was the lowest $(0.4 \%)$. Desorbing agent with $\mathrm{K}$ was more efficient than with $\mathrm{Na}$ in desorbing $\mathrm{Rb}$ because of the closer unhydrated ionic radius of $\mathrm{K}$ and $\mathrm{Rb}$ than $\mathrm{Na}$ and $\mathrm{Rb}$ (Table 2), thus $\mathrm{K}$ was able to effectively exchange with sorbed $\mathrm{Rb}$ inside the $\mathrm{KCoFC}$ lattice. At a higher concentration of $\mathrm{KCl}(1.0 \mathrm{M})$, 98-100\% of Rb desorption from KCoFC was achieved. 


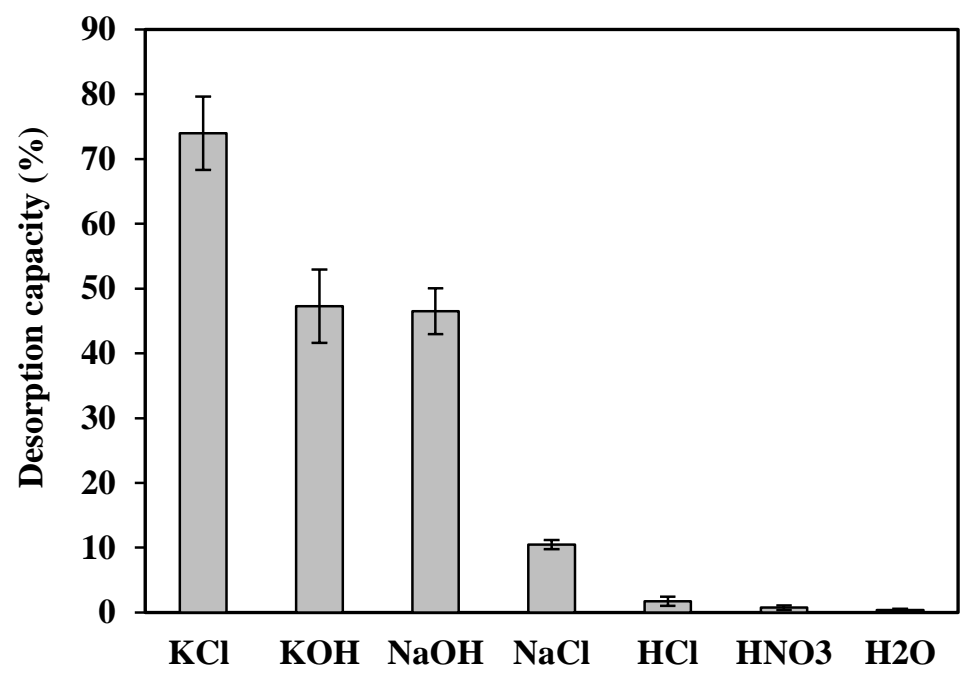

Fig. 10. $\mathrm{Rb}$ desorption with $0.1 \mathrm{M}$ desorbing reagents (after sorption at $\mathrm{C}_{\mathrm{o}}=5 \mathrm{mg} / \mathrm{L}, \mathrm{KCoFC}$ dose $0.1 \mathrm{~g} / \mathrm{L})$.

\section{Conclusions}

The affinity of $\mathrm{KCoFC}$ sorbent for Rb was evaluated using a laboratory prepared KCoFC (KCoFC(L)). Detailed characterisation (chemical composition, SEM-EDX and XRD) of $\mathrm{KCoFC}(\mathrm{L})$ established its similarity to the commercial $\mathrm{KCoFC}$. The major findings for the $\mathrm{Rb}$ sorption characteristics of $\mathrm{KCoFC}(\mathrm{L})$ are as follows:

- $\mathrm{Rb}$ sorption increased from $\mathrm{pH} 3$ to 7 and remained the same at $\mathrm{pH} 7$ to 8 , in accordance with the increase of zeta potential negativity.

- $\quad$ Sorption capacity of alkali metals and alkaline earth metal $\mathrm{Ca}$ on $\mathrm{KCoFC}$ followed the decreasing order $\mathrm{Rb}>\mathrm{Cs}>\mathrm{Li}, \mathrm{Na}, \mathrm{Ca}$. The higher sorption capacity of $\mathrm{Rb}$ compared to the other metals had two explanations. Firstly, it is due to greater surface sorption on the $\mathrm{KCoFC}$ as a result of its lower hydrated ionic radii. This was supported by the observation that the negative zeta potential of $\mathrm{KCoFC}$ was lower for $\mathrm{Rb}$ than for $\mathrm{Li}, \mathrm{Na}$ and $\mathrm{Ca}$. Secondly, $\mathrm{Rb}$ made a greater penetration into the crystal lattice to replace structural $\mathrm{K}$ in the body centre of $\mathrm{KCoFC}$ than other metals including $\mathrm{Cs}$. Rb released 
the largest amount of $\mathrm{K}$, followed by $\mathrm{Cs}$ due to $\mathrm{Rb}$ and $\mathrm{K}$ sharing similar unhydrated ionic radius. Sorption data for $\mathrm{Rb}$ and $\mathrm{Cs}$ at $\mathrm{pH} 7.0 \pm 0.5$ satisfactorily fitted to the Langmuir sorption model. A higher Langmuir maximum sorption capacity of $96.2 \mathrm{mg} / \mathrm{g}$ was achieved with $\mathrm{Rb}$ compared to $60.6 \mathrm{mg} / \mathrm{g}$ for Cs.

- The $\mathrm{Rb}$ sorption kinetics data fitted satisfactorily to PSO model with intraparticle diffusion and exchange of $\mathrm{Rb}$ with structural $\mathrm{K}$ acting as major rate limiting steps.

- The presence of co-existing elements such as Li, $\mathrm{Na}$ and $\mathrm{Ca}$ only minimally influenced $\mathrm{Rb}$ sorption, thereby indicating the selective sorption of $\mathrm{KCoFC}$ for Rb. Only at higher concentrations did Cs reduce the Rb sorption capacity.

- A high desorption capacity (78-80\%) of $\mathrm{Rb}$ was able to be achieved with $0.1 \mathrm{M} \mathrm{KCl}$. Up to $100 \%$ desorption was possible with $1.0 \mathrm{M} \mathrm{KCl}$.

\section{Acknowledgements}

This work was funded by Australian Research Council Discovery Research Grant (DP150101377). We thank Mr. Phillip Thomas in Adelaide, South Australia for proofreading/editing this paper.

\section{References}

[1] Ghosh, S., Bhagwat, A.R., Renshaw, C.K., Goh, S., Gaeta, A.L., Kirby, B.J., Low-lightlevel optical interactions with rubidium vapor in a photonic band-gap fiber. Phys. Rev. Lett. 97 (2006) 023603.

[2] Jandova, J., Dvořák, P., Formánek, J., Vu, H.N., Recovery of rubidium and potassium alums from lithium-bearing minerals. Hydrometallurgy 119 (2012) 73-76.

[3] Hétet, G., Hosseini, M., Sparkes, B., Oblak, D., Lam, P.K., Buchler, B.C., Photon echoes generated by reversing magnetic field gradients in a rubidium vapor. Opt. Lett. 33 (2008) 2323-2325. 
[4] Hosseini, M., Sparkes, B.M., Campbell, G., Lam, P.K., Buchler, B.C., High efficiency coherent optical memory with warm rubidium vapour. Nat. Commun. 2 (2011) 1-5.

[5] Petersková, M., Valderrama, C., Gibert, O., Cortina, J.L., Extraction of valuable metal ions $(\mathrm{Cs}, \mathrm{Rb}, \mathrm{Li}, \mathrm{U})$ from reverse osmosis concentrate using selective sorbents. Desalination 286 (2012) 316-323.

[6] Jeppesen, T., Shu, L., Keir, G., Jegatheesan, V., Metal recovery from reverse osmosis concentrate. J. Clean. Prod. 17 (2009) 703-707.

[7] Le Dirach, J., Nisan, S., Poletiko, C., Extraction of strategic materials from the concentrated brine rejected by integrated nuclear desalination systems. Desalination 182 (2005) 449-460.

[8] Ye, X., Wu, Z., Li, W., Liu, H., Li, Q., Qing, B., Guo, M., Ge, F., Rubidium and cesium ion adsorption by an ammonium molybdophosphate-calcium alginate composite adsorbent. Colloids Surf., A. 342 (2009) 76-83.

[9] Mohite, B., Burungale, S., Separation of rubidium from associated elements by solvent extraction with dibenzo-24-crown-8, Anal. Lett. 32 (1999) 173-183.

[10] Shamsipur, M., Alizadeh, K., Hosseini, M., Mousavi, M.F., Ganjali, M.R., PVC Membrane and Coated Graphite Potentiometric Sensors Based on Dibenzo-21-Crown7 for Selective Determination of Rubidium Ions. Anal. Lett. 38 (2005) 573-588.

[11] Yang, H., Sun, L., Zhai, J., Li, H., Zhao, Y., Yu, H., In situ controllable synthesis of magnetic Prussian blue/graphene oxide nanocomposites for removal of radioactive cesium in water. J. Mater. Chem. A. 2 (2014) 326-332.

[12] Moon, J., Lee, E., Kim, H., Ion exchange of Cs ion in acid solution with potassium cobalt hexacyanoferrate. Korean J. Chem. Eng. 21 (2004) 1026-1031. 
[13] El-Kamash, A., Evaluation of zeolite A for the sorptive removal of $\mathrm{Cs}^{+}$and $\mathrm{Sr}^{2+}$ ions from aqueous solutions using batch and fixed bed column operations. J. Hazard. Mater. $151(2008) 432-445$.

[14] Saberi, R., Nilchi, A., Garmarodi, S.R., Zarghami, R., Adsorption characteristic of 137Cs from aqueous solution using PAN-based sodium titanosilicate composite. J. Radioanal. Nucl. Chem. 284 (2010) 461-469.

[15] Park, Y., Lee, Y., Shin, W.S., Choi, S., Removal of cobalt, strontium and cesium from radioactive laundry wastewater by ammonium molybdophosphate-polyacrylonitrile (AMP-PAN). Chem. Eng. J. 162 (2010) 685-695.

[16] Gibert, O., Valderrama, C., Peterkóva, M., Cortina, J.L., Evaluation of selective sorbents for the extraction of valuable metal ions $(\mathrm{Cs}, \mathrm{Rb}, \mathrm{Li}, \mathrm{U})$ from reverse osmosis rejected brine. Solvent Extr. Ion Exch. 28 (2010) 543-562.

[17] Tusa, E., Harjula, R., Lehto, J., Use of highly selective ion exchangers for minimization of waste volumes. Proceedings of Waste Management Symposium, Tucson, Arizona, USA, (2001).

[18] Prout, W., Russell, E., Groh, H., Ion exchange absorption of cesium by potassium hexacyanocobalt (II) ferrate (II). J. Inorg. Nucl. Chem. 27 (1965) 473-479.

[19] Nilchi, A., Malek, B., Maragheh, M.G., Khanchi, A., Investigation of the resistance of the potassium copper nickel hexacyanoferrate (II) ion exchanger against gamma irradiation. Radiat. Phys. Chem. 68 (2003) 837-842.

[20] Rusmin, R., Sarkar, B., Liu, Y., McClure, S., Naidu, R., Structural evolution of chitosan-palygorskite composites and removal of aqueous lead by composite beads. Appl. Surf. Sci. 353 (2015) 363-375.

[21] Weber, W., Morris, J., Intraparticle diffusion during the sorption of surfactants onto activated carbon. J Sanit. Eng. Div. Am. Soc. Civ. Eng. 89 (1963) 53-61. 
[22] Mardan, A., Ajaz, R., Mehmood, A., Raza, S., Ghaffar, A., Preparation of silica potassium cobalt hexacyanoferrate composite ion exchanger and its uptake behavior for cesium. Sep. Purif. Technol. 16 (1999) 147-158.

[23] Lehto, J., Paajanen, R., Harjula, R., Selectivity of potassium cobalt hexacyanoferrate (II) for alkali and alkaline earth metal ions. J. Radioanal. Nucl. Chem.164 (1992) 3946.

[24] Vincent, C., Hertz, A., Vincent, T., Barré, Y., Guibal, E., Immobilization of inorganic ion-exchanger into biopolymer foams-Application to cesium sorption. Chem. Eng. J. 236 (2014) 202-211.

[25] Nilchi, A., Khanchi, A., Atashi, H., Bagheri, A., Nematollahi, L., The application and properties of composite sorbents of inorganic ion exchangers and polyacrylonitrile binding matrix. J. Hazard. Mater. 137 (2006) 1271-1276.

[26] Loos-Neskovic, C., Ayrault, S., Badillo, V., Jimenez, B., Garnier, E., Fedoroff, M., Jones, D., Merinov, B., Structure of copper-potassium hexacyanoferrate (II) and sorption mechanisms of cesium. J. Solid State Chem. 177 (2004) 1817-1828.

[27] Yue, Q., Li, Q., Gao, B., Wang, Y., Kinetics of adsorption of disperse dyes by polyepicholorohydrin-dimethylanine cationic polymer/bentonite. Sep. Purif. Technol. 54 (2007) 279-290.

[28] Lee, E.F., Streat, M., Sorption of caesium by complex hexacyanoferrates iv. ion exchange kinetics and mechanism of sorption by potassium copper ferrocyanide. J. Chem. Technol. Biotechnol. 33 (1983) 87-96. 